\title{
Educational demands of family members of children with special health care needs in the transition from hospital to home
}

\author{
Demandas educativas de familiares de crianças com necessidades especiais de saúde na transição hospital casa \\ Demandas educativas de familiares de niños con necesidades especiales de salud en la transición hospital-hogar
}

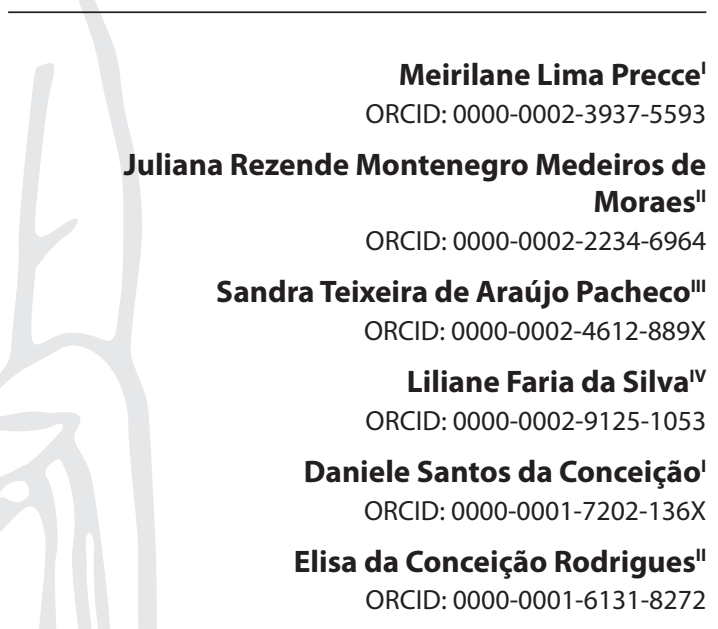

IInstituto Nacional de Saúde da Mulher, da Criança e Adolescente Fernandes Figueira. Rio de Janeiro,

Rio de Janeiro, Brazil.

"Universidade Federal do Rio de Janeiro. Rio de Janeiro, Rio de Janeiro, Brazil.

I'Universidade Estadual do Rio de Janeiro. Rio de Janeiro, Rio de Janeiro, Brazil.

"Universidade Federal Fluminense. Niterói, Rio de Janeiro, Brazil.

How to cite this article:

Precce ML, Moraes JRMM, Pacheco STA, Silva LF, Conceição DS, Rodrigues EC. Educational demands of families of children with special health care needs in the transition from hospital to home.

Rev Bras Enferm. 2020;73(Suppl 4):e20190156 doi: http://dx.doi.org/10.1590/0034-7167-2019-0156

\section{Corresponding author:}

Meirilane Lima Precce

E-mail: meiriprecce@hotmail.com

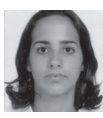

EDITOR IN CHIEF: Antonio José de Almeida Filho ASSOCIATE EDITOR: Rafael Silva

\section{ABSTRACT}

Objectives: to analyze the educational demands of family members of children with special health care needs in the transition from hospital to home Methods: qualitative research conducted between February and June 2018, using the handbook on creativity and sensitivity dynamics, from the sensitive creative method; the participants were nine family caregivers of children admitted to a public hospital in Rio de Janeiro; the data were subjected to French discourse analysis Results: the educational demands were clinical, centered on the categories complex and continuous care, technological care, modified habits, medication, development and mixed care, and social, related to the supplies and rights of children Final Considerations: the social educational demand has emerged as a new demand to be incorporated in the care of these children. The transition from hospital to home should be progressive and have the nurse as its coordinator, with the objective of providing participatory, safe, quality care, articulated within a social network

Descriptors: Child Health; Health Education; Transitional Care; Health Services Needs and Demand; Family

\section{RESUMO}

Objetivos: analisar as demandas educativas dos familiares de crianças com necessidades especiais de saúde na transição do hospital para casa. Métodos: pesquisa qualitativa realizada entre fevereiro e junho de 2018, por meio, de dinâmicas de criatividade e sensibilidade do Almanaque do método criativo sensível; participaram nove cuidadores familiares de crianças, internadas em um hospital público do Rio de Janeiro, cujos dados foram submetidos a análise de discurso francesa. Resultados: as demandas educativas foram de origem clínica centrada nos cuidados complexo e contínuo, tecnológico, habitual modificado, medicamentoso, de desenvolvimento, misto e de origem social, relacionada aos insumos e direitos das crianças. Considerações Finais: a demanda educativa social emergiu como uma nova tipologia a ser incorporada ao conjunto de cuidados dessas crianças. A transição do hospital para casa deve ser processual, tendo o enfermeiro como coordenador, visando um cuidado participativo, seguro, com qualidade e articulado dentro de uma rede social.

Descritores: Saúde da Criança; Educação em Saúde; Cuidado Transicional; Necessidades e Demandas de Serviços de Saúde; Família.

\section{RESUMEN}

Objetivos: analizar las demandas educativas de los familiares de niños con necesidades especiales de salud durante la transición desde el hospital hasta el hogar. Métodos: se trata de una investigación cualitativa realizada entre febrero y junio de 2018, mediante dinámicas de creatividad y sensibilidad del Almanaque del método creativo sensible; participaron nueve cuidadores, familiares de niños internados en un hospital público de Río de Janeiro cuyos datos se sometieron al análisis del discurso francés. Resultados: las demandas educativas eran de origen clínico centralizadas en los cuidados complejo y continuo, tecnológico, habitual modificado, medicamentoso, de desarrollo, mixto y de origen social y estaban relacionadas con los insumos y derechos de los niños. Consideraciones Finales: la demanda socioeducativa emergió como una nueva tipología a ser incorporada al conjunto de cuidados de dichos niños. La transición del hospital al hogar debe ser procesal, teniendo al enfermero como coordinador, con miras a un cuidado participativo, seguro, de calidad y articulado dentro de una red social.

Descriptores: Salud del Niño; Educación de la Salud; Cuidado Transicional; Necesidades y Demandas de los Servicios de Salud; Familia. 


\section{INTRODUCTION}

Children with special health care needs (CSHCN) is an expression used nationally and internationally to refer to children who have chronic, physical, developmental, behavioral or emotional conditions and thus make greater use of health services and require assistance from different professionals, including nursing professionals ${ }^{(1-2)}$.

In Brazil, CSHCN are classified into six categories, according to the demands of care. The developmental category consists of children with delayed development, who require psychomotor therapy and social rehabilitation services more than other children. The technological care category includes children who use life-support devices such as gastrostomy, tracheostomy, colostomy, and others. In the medication category are those who require long-term use of medication such as insulin, anticonvulsants, and others. The modified habits category encompasses children who need adaptations in routine activities such as eating, walking, bathing, and others. The mixed care category is composed of children who have more than one of the previous demands, except for technological care. And finally, the complex clinical care category refers to children with all of these demands, including life support technologies ${ }^{(1-2)}$.

CSHCN, with their care demands and chronic conditions, have to rely on tertiary health care services, recurrent and prolonged hospitalizations, difficult access to primary care and comprehensive care in the Unified Health System (SUS). Despite of the prolonged hospitalizations, family members of CSHCN reported lack of knowledge and misinformation regarding the transition from hospital to home, a moment marked by fear and doubt ${ }^{(3)}$.

Studies show that the current models for hospital discharge preparation are fragmented and place a high burden on family caregivers ${ }^{(4)}$, who claim that they were not prepared by health professionals to meet the care demands of children at home ${ }^{(3,5)}$.

Given the CSHCN' often continuous and complex demands, learning how to provide care in the transition from hospital to home is a challenge for the family caregiver. Therefore, nurses must understand the reality of the families and identify the educational demands, which are the information that must be acquired and learned as part of discharge planning ${ }^{(1)}$.

International and national studies recommend that discharge planning includes educational interventions with family members, as they need to be prepared to receive their children at home ${ }^{(6-7)}$. The nurse has been highlighted in the literature as the most appropriate professional to develop strategies to promote knowledge with the family caregiver, to coordinate comprehensive care and the transition from hospital to home, and to advocate for CSHCN and their families, as they have specialized training and knowledge of health issues ${ }^{(7-9)}$.

Therefore, the nurse must promote a dialogic education process with the family caregivers of CSHCN in the transition from hospital to home, aiming to know their realities and identify educational demands, to create a space for listening, learning and exchange of experience between the family members and to reduce doubts, anxiety and difficulties related to the care of CSHCN.

\section{OBJECTIVES}

To analyze the educational demands of family members of children with special health care needs in the transition from hospital to home.

\section{METHODS}

\section{Ethical aspects}

Given the ethical and legal issues related to the research, data collection only began after the research was approved by the Research Ethics Committee of the studied institution, under protocol number CAAE78848517.8.3001.5269 and all participants read and signed the Informed Consent Form. The Form was presented and delivered to participants on a day different from when the data collection occurred, when a date for the meeting was scheduled, according to the availability of the participant. For an accurate registration, all the dynamics were audio recorded in MP3 player, with prior knowledge and authorization from family members.

\section{Theoretical framework}

In the transition of CSHCN from hospital to home, it is necessary to think about preparing the family in a progressive and gradual manner, involving the caregivers and respecting their spatial and temporal roots, knowledge and skills. Transitions are closely related to time and movement, and they can affect health, relationships, expectations and abilities, as the person has to incorporate new knowledge $\mathrm{e}^{(10-11)}$.

Meleis' theory, which is part of the theoretical foundation of this study, points out that situational transitions are associated with changes in roles in the various contexts in which people are involved. Health-disease transitions encompass sudden changes in role when a person goes from a state of health to an acute or chronic disease or from a chronic state to a state of well-being, which still includes the chronic condition. Organizational transitions happen in people's environment and are anticipated by changes that occur at the social, political and economic context ${ }^{(10-11)}$.

The transition of CSHCN from hospital to home must always be based on a liberating education, guided by Freire's concepts of awareness and dialogicity. In this sense, Freire ${ }^{(9)}$, who is the second theoretical framework adopted in this study, affirms that a valid education must start from the concrete person and their concrete reality, considering them as humans as this is their ontological vocation. However, this is an educative and transitional process that only makes sense if it is based on dialogue and on a genuine concern with the real needs and autonomy of these families, which are seen here as learners and participants of the teaching-learning process ${ }^{(12)}$.

\section{Type of study}

Descriptive study with a qualitative approach, following the Creative and Sensitive Method ${ }^{(13)}$, based on the epistemological frameworks of critical reflection on participant research, group dynamics of social psychology and artistic creation in art-based research. The Creativity and Sensitivity Dynamics (CSD) called Handbook was implemented from February to June 2018, through four group meetings with nine relatives of $\mathrm{CSHCN}$, which lasted for an average of 55 minutes.

\section{Methodological procedures}

\section{Study setting}

The study was conducted at a public hospital specialized in pediatrics in the city of Rio de Janeiro. 


\section{Data source}

Data collection occurred through four group meetings, where the Handbook Creativity and Sensitivity Dynamics (CSD) was applied to nine family caregivers who accompanied CSHCN in the pediatric inpatient unit. This CSD worked as a group meeting and an educational process with the study participants, as they were able to exchange information, experiences and knowledge with each other based on the care they provided to their CSHCN.

The first group was composed of two family members, the research assistant and the main researcher, while the other three groups had three family members, the research assistant and the main researcher. Two family members were present in two distinct groups.

\section{Data collection and organization}

The selection and enrollment of participants was based on the consultation of medical records of patients admitted to the institution and invitation of those who met the following inclusion criteria: relatives of CSHCN with recurrent hospitalizations (more than 3 hospitalizations per year) and/or prolonged hospitalizations (more than 30 days), who were over 18 years old, who were caregivers of the CSHCN and who were available to interact in groups. The exclusion criteria were: relatives who had cognitive difficulties and relatives who were not the caregivers of the child, even if they accompanied them to the hospital occasionally.

Participants who met the inclusion criteria were personally invited by the first author of the article when they were alone, so they did not feel embarrassed and were not identified as participants of a research. All those invited agreed to participate in the study. During this invitation, the researcher explained, in clear and accessible language, the objective of the study and that the CSD would occur in a group with other family members of CSHCN, lasting up to 60 minutes, in a private room in the institution. Upon acceptance, a formal invitation was made and a date for the dynamic was scheduled according to the availability of the participants.

The speeches of the participants were identified by the code name participant and the Arabic number corresponding to the order of their inclusion in the CSD (Participant1, Participant 2, Participant 3, etc....). The objective of the CSD handbook was to know the educational demands of family members of CSHCN in the transition from hospital to home. The following question was the basis for the creation of an artistic piece: "To care for my child at home I must know..."

The CSD handbook was planned after the acceptance of the family members, when scientific literature was consulted to determine the care demands of the CSHCN selected. The dynamic occurred with images and figures that portrayed care of children with special health care needs, such as hygiene, feeding, mobility, among others, both in the hospital and at home, provided by the first author of the article. The image search was conducted in February 2018 on the Google website: www.google.com.br. The results were filtered to find images with permission to use. For this purpose, the Advanced Search filter called "usage rights" was used and the "free to use or share" option was selected, which allows using the content as long as it is not modified.
Participants took brief notes of their key ideas about the initial question, and then attached the response images and figures on a sheet of paper, building a collective handbook. In each group a new handbook was built, totaling four of them.

Data collection occurred during the Handbook Creativity and Sensitivity Dynamics (CSD), conducted by the main researcher, with the help of a trained research assistant with practice in applying CSD. The main researcher conducted the dynamic, stimulating the participants like a cultural animator. The research assistant contributed by providing the participants with the necessary material, taking relevant notes and recording the audio during the dynamics.

New groups were conducted until the construction of meaning of each demand was understood, since discursive formation is influenced by psychoanalysis, historical materialism and the philosophy of language, and each person's history may change, so it is unlikely that the theme is exhausted.

\section{Analysis of data}

Data were analyzed by French discourse analysis ${ }^{(14)}$ in its three phases. The first was the construction of the textual corpus, in raw empirical material, then transformed into discursive object. The second occurred when the discursive object pointed the clues indicating the analytical devices that constituted the participants' discourse. The third was the passage from the discursive object to the discursive process. The use of analytical devices to reach the understanding of the meanings produced by the research participants is highlighted in this method of analysis ${ }^{(15)}$.

Two categories of analysis emerged: clinical educational demands in the care of CSHCN in the transition from hospital to home; social educational demands of CSHCN and their families in the transition from hospital to home.

\section{RESULTS}

Among the nine family caregivers participating in the CSD, there were seven mothers of CSHCN (06 biological and 01 foster mother), one grandmother and one father. The age of the participants ranged from 24 to 59 years. Family income ranged from no income to three minimum wages. Of the nine families participating in the study, six received social benefits from the government such as the Cash Benefit Program (BPC) and the Bolsa Familia (BF), and for one of the families this was the only source of income. The age of the CSHCN ranged from 4 months to 9 years; all of them had demands of care of modified habits, medication, developmental and technological care, and seven children with these demands also required clinically complex care. The length of hospital stays ranged from 97 days to 1000 uninterrupted days.

Clinical educational demands in the care of CSHCN in the transition from hospital to home

The educational demands presented were related to clinical care, according to the place, space and time of the participants in the transition from hospital to home. They were classified in six types of care demands: clinically complex, technological, modified habits, medication, developmental and mixed care.

Clinically complex care demands place a heavy burden on family caregivers, even during the hospitalization. 
What is happening is that my baby [CSHCN 2] is going be five months old and he has not gone home since he was born [extremely premature], because of his health problems, it is a lot [he has Dandy Walker syndrome, severe intracranial hypertension, an external ventricular drain and gastrostomy]. In the nursery, we [mothers] do not have direct care with the babies, everything was done by them [health care team], when they sent him [CSHCN 2] to the infirmary, I almost went crazyon the first day, it was verynew to me. (Participant 2)

The discourse of Participant 2 reveals that there is a lot of new information to be acquired in order to take care of their CSHCN. Therefore, nurses must create possibilities for the construction of knowledge in a progressive and gradual manner.

Two participants revealed educational needs related to care with the gastrostomy and tracheostomy technologies.

The question I have is when he [CSHCN 2] puts this button and I don't know if I can go home. This button, is it us [mothers] who take it off, how do we clean it, how do I do it here in the hospital? Do I wash it only with saline [physiological 0.9\%] and gauze and at home I continue doing this? We [mothers] have to take this button, take it off, put it on. (Participant 2)

The tracheostomy is fine, but I can't take care of it. The health professionals asked me not to do it [tracheostomy care]. (Participant 6)

Care with technological devices in the child's body is a scientific knowledge that generates educational demands for family members that must deal with this device. When the family members come in contact with these technologies and have to deal with them, they demonstrate the concern to incorporate new knowledge and new skills, which are part of nursing knowledge and competency, so that their children can be cared for at home.

Regarding the modified habit of feeding, it is necessary to understand the educational demands of family caregivers in order to help in the transition from hospital to home.

We are studying the ketogenic diet, which helped 100\% and stopped the crises [convulsive]. The convulsive crises are very rare for her [CSHCN 1], really really rare, and sometimes we do not realize she is having a crisis [convulsive] because it is too fast, before this diet they were very long. (Participant 1)

We have this problem with feeding, with fruits, it is very difficult for her to eat fruit, my God! We try to give her fruits [CSHCN 9], we offer, but it is very hard. It is still a bit complicated to find a strategy for her to eat fruits. She [CSHCN 9] doesn't eat. (Participant 9)

Participant 1, in conjunction with hospital professionals, are experimenting with a different diet, with high-fat, low-carb, and normal-protein foods, called ketogenic diet, which is used primarily to treat difficult-to-control epilepsy in children. For Participant 9, the educational demand is about making their daughter eat fruit.

In medication care, the educational demand was related to the administration of medication, what to do in case of seizures and home poisoning.

Because as I was already a mother, I had the ability to keep everything saved in my phone, the time of medication, I already have everything in mind. I always look to see if it is already medication time, because when I go out, Ileave the medication already diluted in the syringe, you just have to give it on the right time. This is a matter of custom, you get used to it. She [CSHCN 1] takes four very strong anticonvulsants and sometimes we are afraid of poisoning. (Participant 1)

At home, we have to know how to manage it [anticonvulsants]. In convulsive crises, if they happen, what do you do? This medication, if I forget it, will it trigger a seizure? (Participant 2)

The experience of being a mother to another child and caring for a child with special health care needs who was already at home, gave Participant 1 the organization and expertise of already diluting medications. However, the number of anticonvulsants used to control seizures triggers the fear and the educational demand related to poisoning. Participant 2, who has been living with their child for less time and has never been home with him, has educational demands regarding the administration of anticonvulsants, what to do if they forget to administer the dose and the possible consequences for the child.

The developmental care demand was related to how to do physical therapy exercises with the CSHCN.

My daughter's body is very soft [she has developmental delay due to encephalopathy], she's hypotonic. I look it up on the internet [physical therapy exercises], but what's the good of seeing it on the internet and not knowing how to do it, what if I do a wrong exercise and hurt the femur, hurt something? I hold her like a baby [CSHCN 1] because she is very soft, but we always have that fear of getting it wrong. (Participant 1)

In an attempt to do physical therapy exercises on their daughter, Participant 1 tries to solve their educational demands through internet videos. However, they are not trained on how to do it and are afraid of causing any harm, as they do not know how to properly handle the child who is hypotonic.

\section{Social educational demands of CSHCN and their families in the transition from hospital to home}

The social educational demand was present in the discourse of the participants and was related to the right of getting a supply of special milk, access to school, the social benefits guaranteed by the State and access to school life.

And he [CSHCN 2] is only four months old, and he needs special milk. I was wondering where I can go, what can I do so that he [CSHCN 2] can get this [special] milk, if he is discharged today. But he can only go home if he has this [special] milk, so what do I do? [...] Also known as Cash Benefit Program of the Organic Law on Social Assistance Welfare Law [BPC/LOAS]. The law guarantees free public transport, payment of a minimum wage, medical treatment in another state, among other benefits guaranteed by law 8742. Here's the rights and benefits of people with special needs" [Participant 2 reads the sentences that composed the creation of their Handbook]. It's just that I haven't been oriented yet and wanted to know about these issues. (Participant 2)

I tried to put S. [CSHCN 4] in a school about 4 years ago, but at the time they had no companion [school support professional], today he is 4 and has never been to school. (Participant 4) 
Participant 2 had several questions, as they did not know and had not received guidance on the rights of their child (CSHCN 1), who was 4 months old and had been hospitalized since birth.

CSHCN 4 had been hospitalized for three years, due to their continuous clinically complex care; however, before this hospitalization, the mother (Participant 4) tried to enroll her child in a school, but the Brazilian Inclusion of People with Disabilities Act (published on July 6, 2015) did not yet exist, impairing the social inclusion of CSHCN 4.

Figure 1 below shows the images and texts related to the social educational demands selected by participants 3, 4 and 5 in the second CSD Handbook:

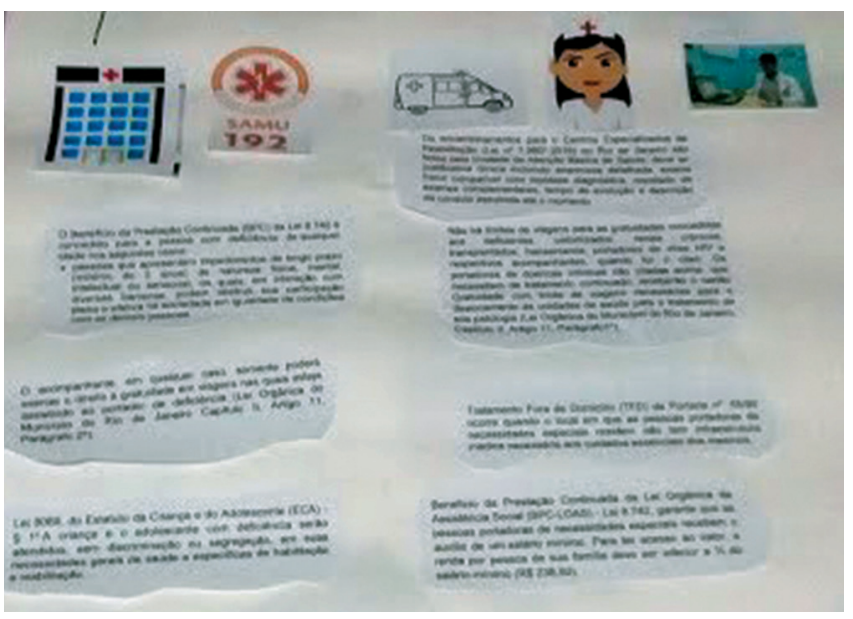

Note: CSD - Creativity and Sensitivity Dynamics.

Figure 1 - CSD Handbook. Created by participants 3, 4 and 5, Rio de Janeiro, Rio de Janeiro, Brazil, 2018

Regarding the rights of CSHCN 3, in relation to the city of Rio de Janeiro, Participant 3 gave the following statement:

The gratuities granted in the Organic Law of the City of Rio de Janeiro will be exercised in the conventional two-door buses, through the presentation of the electronic card [Participant 3 reads the sentence selected by her in the Handbook], which is the Riocard, that every child can have, but up until today, one year later [in Rio de Janeiro], I could not get it [the benefit of free conventional bus] for my son [CSHCN 3], so I think that there is a flaw in their work [for granting the benefit]. (Participant 3)

The educational demand presented by Participant 3 is related to free public transport, given that their child (CSHCN 3) has a chronic disease and is entitled to this benefit, but the guardian of the CSHCN has to present proof of residence in Rio de Janeiro - which Participant 3 does not have, as they live in Espírito Santo.

Regarding social rights, Participant 5 reports difficulties related to transportation:

We [Participant 5 and the father of CSHCN 5] have never looked for it because we know they do not have it [a mobile ICU service in the city of Seropédica], so we don't even look for it. It is his right [CSHCN 5], but the city [Seropédica] does not have it. (Participant 5)

Participant 5 reported their difficulty with the transportation of CSHCN 5, who is 4 years old and requires home care 24 hours a day. In emergencies, Participant 5 hires a private mobile ICU to transport the child to the studied hospital (about $70 \mathrm{~km}$ away).

\section{DISCUSSION}

The educational demands related to clinical care that were presented by the family caregivers of this study were in the categories of complex and continuous care, technological care, modified habits, medication, development and mixed care. The educational demands are those that require greater training of the families, considering that it is the preparation for the transition from hospital to home.

When dealing with a CSHCN with prolonged hospitalizations and complex and continuous care demands, the family usually faces an initial disorganization, with changes in their life routine and habits. This change in family, associated with the transfer of the child and a companion to the hospital, can cause disruption, instability and leave scars in their memories. Difficulties in coping with and accepting this new concrete reality and feelings such as dread, fear and shock may still appear within the family. Thus, with hospitalization, family caregivers of CSHCN have to deal with care that did not belong to their daily routine, experiencing a process of mourning and situational transition ${ }^{(12-15)}$.

The realization of special health care needs, the use of lifesupport technology, and the critical care environment and critical patients are initial obstacles for the care that will be provided by the family. However, with the passage of days, the transfer to less complex hospital sectors and the opportunity to be closer to the child's body with the help of the nurse, the family caregiver can break the barrier of fear and of the unknown ${ }^{(11-12)}$.

It is important to note that, since the moment of hospitalization, the nurse should begin a gradual educational process with this family, having in mind the transition from hospital to home ${ }^{(10)}$ and always avoiding information overload. In this sense, the construction of knowledge about care for children with special health care needs and clinically complex care demands must be based on horizontal communication and respect for the time and space of each caregiver ${ }^{(1,16)}$.

In this context, nurses' work should be focused on the preparation of family caregivers for the provision of care in the hospital, with a view to the moment of discharge. However, discharge needs to be a progressive process and include planning, preparation of the family, and an individualized therapeutic plan for the child, developed in a collaboration between professionals and families and initiated in the admission of the child and not just at the moment of discharge ${ }^{(1)}$.

Therefore, in the health-illness transition ${ }^{(11)}$, the nurse is responsible for providing innovative, complex and continuous care and for educating the family member, respecting their knowledge and stimulating reflection, action and empowerment ${ }^{(12)}$. The literature points out that family members often feel anxious and scared before performing the first care, but the learning process should contribute to reduce this anxiety, improving their selfconfidence and skills $s^{(1,16)}$.

The educational demands associated with technology were related to home and procedural care of tracheostomy and gastrostomy. The importance of nurses as educators is highlighted, 
as they are responsible for guiding family members on this care, so that they learn to manage the technology incorporated in their children's bodies, and can also contribute to overcoming stressful moments. Thus, family caregivers deserve special attention, as the nurse must respond to their needs, which are mainly related to the provision of care ${ }^{(2)}$.

The technological care required for the maintenance of life can be a heavy burden on these caregivers; therefore, these children should be followed up after discharge by the nurse and a multiprofessional team specialized in home care. A study conducted in the United States described a good home-care nurse as someone with skills and experience caring for children, competencies related to medical technology, and knowledge about child-specific needs and traits ${ }^{(17)}$.

The clinical educational demands related to modified habits included the implementation of the ketogenic diet to reduce seizures and the difficulty to include fruits in the diet of the CSHCN. The literature points out that eating practices are the origin of all life habits and all family beliefs.

In the educational process related to the children's diet, the health professional must be aware that it will not always be possible to reproduce the hospital diet at home due to financial issues, availability of foods, cultural habits, among other factors. In this sense, nurses must develop an educational process based on the reality of the family, in a truly dialogic relationship. It is worth noting that, for the implementation of an educational process with family members of CSHCN in the transition from hospital to home, nurses also need to be trained to develop their educational skills ${ }^{(1)}$.

The educational demands related to medication show that it is necessary to provide information and build scientific knowledge on how to administer medication and what to do in case of forgetting the medication doses, as family caregivers take on the care of the child's body. The family caregivers who had other children and who had more experience with the child with special health care needs, including moments at home, could present their care practice as example in the educational process, demonstrating that the nurse is not the only person that can be the mediator in the transition from hospital to home.

The family caregivers of CSHCN develop a support and solidarity network among themselves, and, through their experiences and expertise, can eventually educate other family members ${ }^{(18)}$. Thus, it is possible to overcome the banking model of education, which is aimed at the acquisition of skills and abilities for the execution of a certain technique, and the family caregiver can be at the center of the educational process, since people teach each other, mediated by the world ${ }^{(12)}$.

The educational demand related to the child's development showed that the family caregiver can find other sources for learning, such as the internet. However, in addition to theoretical knowledge, practice is also necessary in this case of physical therapy exercises with CSHCN. When the educational demand is not met by health professionals, family members with a thirst for knowledge seek other sources of information ${ }^{(12)}$.

In this study, social educational demands were prominent and represented a new demand to be incorporated into the educational process in the transition from hospital to home.
Family members of CSHCN not only need to provide clinical care, but also need to know and have access to social benefits, as they often face financial difficulties due to their expenses for specific high-cost care, constant trips to hospitals and health services. rehabilitation, medication, special diets and other materials $s^{(1-7)}$. In addition, CSHCN often require full dedication at home, which is usually provided by mothers who have to leave work, reducing the per capita income of the family, which is often insufficient to meet the minimum demands of these children ${ }^{(19)}$.

In some cases, all family income comes from government financial aid such as the Cash Benefit Program and the Bolsa Familia. However, lack of disclosure about social programs and benefits leads to lack of knowledge about the rights of children with disabilities and a subsequent judicialization to access essential services and equipment ${ }^{(20)}$.

Financial difficulty results in social vulnerability and program deficiencies due to invisible official rates and lack of specific public policies to address the needs of these children, in addition to exposure to illness and death due to discontinuity of medication and health treatment ${ }^{(17,21)}$. Social vulnerability is related to unarticulated actions in various sectors of society, such as: access to special transportation for disabled people and their caregivers, school inclusion with educational support and hospital classes when in the hospital. In addition, CSHCN find barriers to obtain social benefits such as the BPC, the Bolsa Família, their right to receive supplies and special food, among others ${ }^{(19)}$.

A study conducted in Europe found that, on this continent, integration of health services for complex care demands is still insufficient, with wide variation in systems of care for children in different European countries. However, the provision of care closer to home for children is a goal of European international policy. Progress towards achievement of this goal has been slow despite growing evidence that homecare provides a means of mitigating the barriers and isolation children and their families experience during the transition from hospital to home, can significantly reduce hospital utilization, and reduces the cost of care for children living with complex care needs ${ }^{(21)}$.

In Brazil, the Unified Health System (SUS) guarantees equal access to health; however, difficulties to access health services are still present. Therefore, the creation of specific public policies directed at this group is essential to guarantee the provision of qualified material and human resources to meet the health demands of CSHCN in the transition from hospital to home ${ }^{(22)}$.

The guarantee of these rights in current legislation and public policies does not mean they are actually respected. The family must also be educated, oriented, empowered and aware of their rights and the rights of their child, so that they can assure them and, when this does not happen, they can resort to judicial procedures $^{(19)}$.

Regarding the school inclusion of children with special health care needs, a European study highlights that chronic health conditions affect school performance ${ }^{(23)}$. However, in Brazil the difficulty is in school inclusion, although law states that education systems must organize the conditions of access to spaces, pedagogical resources and communication in order to promote learning and valorization of diversity and to meet the educational needs of all students. Accessibility must be ensured through the elimination 
of architectural barriers in the building, including facilities, equipment and furniture, and providing school transportation ${ }^{(24)}$.

International literature indicates that an integrated health service network and coordinated care improves access to services and supplies, reduces emergency care, hospitalizations and hospital charges, and facilitates access to social benefits. International literature also highlights that care coordination programs - which establish continuous care management and favor access to social and care benefits - are broader than traditional discharge planning. These programs ensure that the child can stay as long as possible at home and serve as a central access point and as an educational resource for the families of $\mathrm{CSHCN}^{(25)}$.

\section{Limitations of the study}

This study was developed in a hospital with high technological and professional complexity, located in the city of Rio de Janeiro, which is a Unified Health System reference for the diagnostic investigation and treatment of rare diseases and which has an interdisciplinary home care program for CSHCN. Thus, the characteristics of the participants and of the CSHCN may not be similar to those found in other health units that also provide care for this population. In addition, the number of participants represents a limited sample for the comprehensive generalizations of the results. Therefore, new studies in other contexts of care such as home care and primary health care should be developed.

\section{Contributions to professional nursing practice, health or public policies}

The study is expected to broaden dialogic education and professional institutional practices to favor the transition of CSHCN with clinically complex care demands from hospital to home.

It can also contribute to the formation of teams in which nurses act as care coordinators in the discharge planning for this population, aiming to reduce prolonged and recurrent hospitalizations.

\section{CONCLUSIONS}

The discourse of family caregivers indicated that the educational demands of family members of children with special health care needs in the transition from hospital to home are related to clinical care for the child's body, in the categories of complex and continuous care, technological care, modified habits, medication, development and mixed care. The participants' discourse highlighted social demands, which should be incorporated in the care for CSHCN.

In the development of these educational demands, nurses should assume the role of care coordinators, understanding the transition from hospital to home as a process initiated in the first day of hospitalization and not just near discharge. As coordinator, these professionals must approach the social and cultural reality of families in order to promote an active and participatory educational process, in which family members can expose their doubts, fears and insecurity. Thus, this professional will be contributing to the reflection/action, awareness and empowerment of caregivers.

It should be noted that when the educational process is developed in groups and with other family members, the exchange of experience enhances knowledge and helps overcoming the traditional banking model of education. Family members become the protagonists of the educational process and can help each other based on their experiences and expertise, forming a support and solidarity network.

Therefore, educational demands are centered on clinical and social care and should be addressed in a group educational process with nurses and family members, with the objective of guaranteeing the transition of CSHCN from hospital to home and the provision of participatory, safe and quality care within a social and health care network.

\section{REFERENCES}

1. Góes FGB, Cabral IE. Discourses on discharge care for children with special healthcare needs. Rev Bras Enferm. 2017;70(1):154-61. doi: 10.1590/0034-7167-2016-0248

2. Viana IS, Silva LF, Cursino EG, Conceição DS, Góes FGB, Moraes JRMM. Educational encounter of nursing and the relatives of children with special health care needs. Texto Contexto Enferm. 2018;27(3):e5720016. doi: 10.1590/0104-070720180005720016

3. Lima MF, Paulo LF, Higarashi IH. Technology-dependent children: the meaning of home care - a descriptive study. O Braz J Nurs. 2015;14(2):178-89. doi: 10.17665/1676-4285.20155191

4. Solan LG, Beck AF, Brunswick, SA, Sauers HS, Wade-Murphy S, Simmons JM, Shah SS, Sherman, SN. The family perspective on hospital to home transitions: a qualitative study. Pediatr. 2015;136(6):e1539-49. doi: 10.1542/peds.2015-2098.

5. Dias BC, Ichisato S, Marchetti, MA, Neves ET, Higarashi IH, Marcon SS. Challenges of family caregivers of children with special needs of multiple, complex and continuing care at home. Esc Anna Nery. 2019;23(1):e20180127. doi: 10.1590/2177-9465-EAN-2018-0127

6. Aboneh EA, Chui MA, Care coordination, medical complexity, and unmet need for prescription medications among children with special health care needs. Res Social Adm Pharm. 2017;13(3):524-529. doi: 10.1016/j.sapharm.2016.05.043

7. Cabral IE, Moraes JRMM. Family caregivers articulating the social network of a child with special health care needs. Rev Bras Enferm. 2015;68(6):769-76. doi: 10.1590/0034-7167.2015680612i.

8. Caicedo C. Children with special health care needs: Child health and functioning outcomes and health care service use. Journal of Pediatric Health Care. 2016;30(6):590-98. doi: 10.1016/j.pedhc.2015.12.003. 
9. Esteves JS, Silva LFS, Conceição DS, Paiva ED. Families' concerns about the care of children with technology-dependent special health care needs. Invest Educ Enferm. 2015;33(3):547-55. doi: 10.17533/udea.iee.v33n3a19.

10. Chick N, Meleis Al. Transitions: a nursing concern. In: Chinn PL. Nursing research methodology. Maryland: Aspen; 1986. 237-257p.

11. Santos EJF, Marcelino LMMMS, Abrantes LCB, Marques CFF, Correia RML, Coutinho EC et al. Human transitional care as a nursing focus: contribution of expertise and classified language ICNP®. Millenium [Internet]. 2015 [cited 2017 Jul 20];49:153-171. Available from: http:// www.ipv.pt/millenium/Millenium49/9.pdf

12. Freire P. Educação como prática da liberdade. 40 ed. Rio de Janeiro: Paz e Terra; 2017. 190p.

13. Cabral IE, Neves ET. Pesquisar com o método criativo e sensível na enfermagem: fundamentos teóricos e aplicabilidade. In: Lacerda MR, Costenaro RGS, organizador. metodologia da pesquisa para a enfermagem e saúde: da teoria à prática. Porto Alegre: Moriá; 2015. 496p.

14. Orlandi EP. Análise de discurso: princípios e procedimentos. Campinas (SP): Pontes; 2015. 100p.

15. Antônio S, Pacheco STA, Gomes MPF, Bossa PMA, Castro FMC, Pereira MCR. Translations of Family members' feelings in caring for children dependent on clean intermittene catheterization. Rev Enferm UERJ. 2016;24(4):e19990. doi: 10.12957/reuerj.2016.19990

16. Marques GMV, Santos NA, Junior FGR, Feijão GMM, Lins CFM. Intervention with parents and caregivers as assistance strategy for persons with special needs. Rev Fund Care Online. 2018;10(2):374-378. doi: 10.9789/2175-5361.2018.v10i2.374-378

17. Zanello E, Calugi S, Rucci P, Pieri G, Vandini S, Faldella G, et al. Continuity of care in children with special healthcare needs: a qualitative study of family's perspectives. Ital J Pediatr. 2015;8:41-7. doi: 10.1186/s13052-015-0114-x

18. Nageswaran S, Golden SL. Improving the quality of home health care for children with medical complexity. Acad Pediatr. 2017;17(6):665671. doi: 10.1016/j.acap.2017.04.019

19. Okido ACC, Cunha ST, Neves ET, Dupas G, Lima RAG. Technology-dependent children and the demand for pharmaceutical care. Rev Bras Enferm. 2016;69(4):671-7. doi: 10.1590/0034-7167.2016690415i.

20. Ramos LDC, Moraes JRMM, Silva LF, Góes FGB. Maternal care at home for children with special needs. Invest Educ Enferm. 2015;33(3):492499. doi: 10.17533/udea.iee.v33n3a13

21. Brenner M, Miriam O'Shea M, Larkin PJ, Kamionka SL, Berry J, Hiscock H, et al. Exploring integration of care for children living with complex care needs across the European Union and European economic area. Int J Integr Care. 2017;17(2):1-5. doi: 10.5334/ijic.2544

22. Neves ET, Silveira A, Arrué AM, Pieszak GM, Zamberlan KC, Santos RP. Network of care of children with special health care needs. Texto Contexto Enferm. 2015;24(2):399-406. doi: $\quad$ 10.1590/010407072015003010013

23. Hoffmann I, Diefenbach C, Gräf C, König J, Schmidt MF, Schnick-Vollmer K, et al. Chronic health conditions and school performance in first graders: a prospective cohort study. PLoS ONE 2018;13(3):e0194846. doi: 10.1371/ journal.pone.0194846

24. Ministério da Educação (BR). Portaria n 948, de 09 de outubro de 2007. Política Nacional de Educação Especial na Perspectiva da Educação Inclusiva[Internet]. Brasília: Ministério da Educação; 2008[cited 2017 Sep 20]. Available from: http://portal.mec.gov.br/arquivos/pdf/ politicaeducespecial.pdf

25. Petitgout JM. The financial impact of a hospital-based care coordination program for children with special health care needs. J Pediatr Health Care. 2018;32(1)3-9. doi: 10.1016/j.pedhc.2017.06.003 